\title{
Reseña bibliográfica de: Ferguson, S. (2020). Women and Work Feminism, Labour, and Social Reproduction. London: Pluto Press. 193 pp.
}

Palabras clave: Reproducción Social; Trabajo Femenino; Teorías Feministas.

Keywords: Social Reproduction; Women's Work; Feminist Theories.

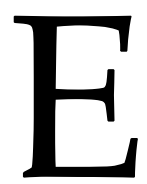

sta obra de Susan Ferguson forma parte de la serie sobre feminismos y reproducción social editada por Tithi Bhattacharya (2017), y es un aporte sustancial para pensar los alcances y limitaciones de la "teoría de la reproducción social", que volvió a llamar la atención de la academia y de los movimientos feministas a finales de la década del 2000 por su potencial para abordar y explicar las nuevas dinámicas de explotación y discriminación a nivel global generadas a partir de la crisis económica desatada en 2008. El tema central del libro indaga en las diferentes formas en las que los feminismos han entendido al trabajo de las mujeres y su relación con la opresión. La investigación hace un recorrido de las posiciones feministas asociadas con diferentes tradiciones políticas -desde la democracia radical de 1790, pasando por el socialismo utópico del siglo XIX, hasta la campaña del colectivo internacional de salarios por el trabajo doméstico en la década de 1970 y el actual proyecto de un "feminismo para el 99\%" (2019)- para dar cuenta de los puntos de encuentro y de desencuentro entre las que Ferguson llama las "tres grandes trayectorias" de los feminismos de los siglos XVIII, XIX y XX.

A partir del rastreo de las teorías feministas sobre el trabajo a través de su historia, la autora conceptualiza a estas tres trayectorias como: el feminismo igualitario (equality feminism); el feminismo socialista (critical equality); y los feminismos de la reproducción social (social reproduction feminism). La motivación del libro no está planteada solo desde un lugar académico, sino también político. Ferguson reconoce que las trayectorias rescatadas, coexisten todavía hoy entre muchas otras y juegan un papel fundamental en la configuración de las luchas políticas y sociales. En esa línea, nos advierte que ninguno de los rasgos de las trayectorias feministas descriptas debe tomarse como definitivos o estáticos y que el feminismo de la reproducción social es una teoría en permanente crítica y construcción, que intenta desafiar las viejas nociones de lo que es el trabajo.

Partiendo del contexto del proceso de la acumulación originaria y su repercusión en el trabajo para las mujeres explicado por Marx en El Capital, la autora plantea que la perspectiva que ha dominado históricamente al socialismo feminista ha limitado su 
potencial para desarrollar un trabajo político integral en la clase trabajadora. Al mismo tiempo, las trayectorias feministas no son analizadas desde la división entre feministas burguesas y feministas socialistas, sino que son desarrolladas a partir de su contexto histórico que les brindó una matriz de pensamiento común. Por último, gran parte de la mirada de la autora incluye la incorporación de la perspectiva de los feminismos negros de manera transversal en su obra. Ferguson señala, acertadamente, que ninguna de las tres trayectorias contemplaba la "racialidad" al pensar sobre el trabajo femenino, por lo que nos insta a integrar analíticamente las formas en las que el racismo también definió al trabajo femenino.

La obra se estructura en dos grandes secciones. Una primera sección de cuatro capítulos dedicada a las trayectorias de equality feminism, critical equality feminism, y el feminismo antirracista. Por su parte, la segunda sección analiza al feminismo de la reproducción social, el famoso debate sobre el trabajo doméstico y las corrientes de pensamiento que se desprendieron de él, y los desafíos a los que se enfrenta una "renovación" de la teoría de la reproducción social en la actualidad. La primera parte del libro describe cómo el feminismo igualitario, que encuentra sus raíces a fines del siglo XVIII con los escritos de Mary Wollstonecraft, desarrolló una crítica de la división sexual del trabajo: la marginación de las mujeres a trabajos infravalorados reforzó su vulnerabilidad y dependencia económica hacia la arbitrariedad de sus padres y esposos. La emancipación estaba, por lo tanto, en la independencia de los hombres por medio del acceso a trabajos asalariados y a la educación formal. Ferguson ubica esta aproximación en la tradición racional-humanista muy típica de la Ilustración europea de los siglos XVIII y XIX, pero no sería la única.

En el capítulo siguiente se demuestra cómo los socialistas utópicos Anna Wheeler y William Thompson (1825) redactaron el primer análisis político-económico del trabajo doméstico de las mujeres, desmarcándose de aproximaciones humanistas sobre el trabajo doméstico. Este texto sentó las bases del feminismo de la reproducción social al partir de plantear que para entender la opresión de la mujer hay que preguntarse cómo y porque se devaluó el trabajo doméstico. Su aporte fue llamar la atención sobre la interacción entre trabajo asalariado y gratuito, posicionándolos como partes diferentes pero esenciales de un mismo sistema social de acumulación de riqueza. Desde ahí, Ferguson analiza comparativamente la trayectoria del critical equality feminism y del feminismo de la reproducción social. Si bien la perspectiva de las socialistas feministas comparte con el feminismo de la reproducción social la crítica a la separación capitalista entre trabajo productivo y reproductivo, la primera hizo hincapié en la división sexual del trabajo, adoptando el marco racional-humanista de pensamiento que el feminismo igualitario. Al mismo tiempo, el socialismo feminista llevaba su razonamiento críticamente un poco más lejos al afirmar que la participación de las mujeres en la fuerza de trabajo, además de liberarlas del sojuzgamiento de los varones, fortalecía la lucha de clases contra el capitalismo. Así, el socialismo feminista combinó las dos formas de análisis: una crítica racional-humanista del trabajo no pago de las mujeres y una crítica 
política-económica al trabajo asalariado. Esta perspectiva desarrollada en el capítulo 4 explicaría, según Ferguson, por qué las socialistas feministas tendieron hacia el dualismo teórico (es decir, la tendencia a concebir al patriarcado y al capitalismo como dos sistemas autónomos), fallando en la teorización sobre las relaciones entre ambas formas de trabajo.

La última parte de esta primera sección retoma los aportes y las críticas de las tradiciones de las feministas antirracistas, cuyos manifiestos rebasaron los límites de estas dos trayectorias feministas blancas e hicieron foco en las realidades particulares de las mujeres de color y su relación con el trabajo doméstico, dando por tierra con cualquier teoría universalizante que encontrara la causa de la opresión de las mujeres en el trabajo doméstico en sí mismo.

La segunda parte del libro versa sobre el feminismo de la reproducción social y su innovación teórica de concebir a la lucha feminista como lucha anti-capitalista y clasista. $\mathrm{Al}$ adentrarse en las principales características del feminismo de la reproducción social en el capítulo seis, Ferguson selecciona a aquellas pensadoras que han contribuido al debate que divide hasta la actualidad a las feministas de la reproducción social: la producción o no de valor del trabajo doméstico. ${ }^{1}$ Desde las conclusiones de ese debate, en el cual la autora se posiciona explícitamente a favor de lo que llama la "escuela marxista", se analizan las fortalezas y las debilidades del feminismo de la reproducción social y los nuevos desafíos teórico-políticos a los que se enfrenta. Estos son desarrollados en el capítulo 7, en el cual se plantea la necesidad de una renovación de la teoría de la reproducción social a partir de la cual se logre explicar la opresión de las mujeres incorporando otros elementos (como la raza) y que permita quitar el foco del trabajo doméstico hacia una mirada más amplia del trabajo reproductivo en relación con el trabajo productivo. Para Ferguson, el punto de partida de esta renovación estaría en la consideración de que el "trabajo femenino" puede ser pago o impago, desarrollado en los hogares, en las comunidades, o incluso en los lugares de trabajo asalariado. Y aunque frecuentemente presenta un perfil generizado (gendered), dicho trabajo no tiene que ser llevado a cabo necesariamente por mujeres. Atendiendo así a la dualidad del trabajo (su forma concreta y su forma abstracta), el feminismo de la reproducción social enfatiza las contradicciones entre la creación de valor (en el sentido explicado en El Capital de Marx) y la creación de la vida. Pone su atención en el hecho de que mientras que el trabajo (productivo y reproductivo) siempre está sujeto a la disciplina capitalista, al mismo tiempo la excede y da como resultado que, quienes desarrollan trabajos de reproducción social, tienen el potencial de organizar el trabajo para la vida, no para el capital.

\footnotetext{
${ }^{1}$ Las dos tendencias que identifica son la "marxista autonomista" representada por Federici, Dalla Costa y Mezzadri (entre otras) y la "escuela marxista de la reproducción social", en la que se ubica la misma Ferguson, Bhattacharya y Arruzza (Ferguson 2020, 122-123).
} 


\section{Referencias bibliográficas}

Arruzza, C., Bhattacharya, T. y Fraser, N. (2019). Feminism for the 99 Percent: A Manifesto. New York: Verso Books.

Bhattacharya, T. (2017). Social Reproduction Theory Remapping Class, Recentering Oppression. London: Pluto Press.

Thompson, W. [y Doyle Wheeler, A.] (1825). Appeal of one half the human race, women: Against the pretensions of the other half, men, to retain them in political, and thence in civil and domestic, slavery: In reply to a paragraph of Mr. Mill's celebrated "Article on Government." London: Longman, Hurst, Rees, Orme, Brown, and Green.

\section{Velia Luparello}

Centro de Investigaciones y Estudios sobre la Cultura y Sociedad (CONICET-UNC), Argentina Luparello.vs@gmail.com

Para citar este artículo:

Luparello, Velia (2020). Reseña bibliográfica: “Ferguson, S. (2020). Women and Work Feminism, Labour, and Social Reproduction. London: Pluto Press. 193 pp." Anuario de la Escuela de Historia Virtual, 18, 277-280. 